\title{
Epidemiologic Evidence Concerning the Bereavement Exclusion in Major Depression
}

\section{Citation}

Gilman, Stephen E., Joshua Breslau, Nhi-Ha Trinh, Maurizio Fava, Jane M. Murphy, and Jordan W. Smoller. 2012. "Epidemiologic Evidence Concerning the Bereavement Exclusion in Major Depression." Archives of General Psychiatry 69 (11) (November 1): 1179. doi:10.1001/ archgenpsychiatry.2012.383.

\section{Published Version}

doi:10.1001/archgenpsychiatry.2012.383

\section{Permanent link}

http://nrs.harvard.edu/urn-3:HUL.InstRepos:26846086

\section{Terms of Use}

This article was downloaded from Harvard University's DASH repository, and is made available under the terms and conditions applicable to Other Posted Material, as set forth at http:// nrs.harvard.edu/urn-3:HUL.InstRepos:dash.current.terms-of-use\#LAA

\section{Share Your Story}

The Harvard community has made this article openly available.

Please share how this access benefits you. Submit a story.

\section{Accessibility}


Epidemiologic Evidence Concerning the Bereavement Exclusion in Major Depression

$\mathrm{T}$ here has been considerable debate over the validity of the bereavement exclusion in the diagnosis of major depressive episode (MDE) and much controversy about whether the bereavement exclusion should be maintained in DSM-5. Mojtabai investigated the issue using data from the National Epidemiologic Survey on Alcohol and Related Conditions and concluded that the bereavement exclusion should be maintained in DSM-5. ${ }^{1}$ We analyzed the same data and came to a different conclusion. ${ }^{2}$ Herein, we discuss why we think our 2 studies arrived at different conclusions and their implications for revising the diagnostic criteria.

Both of our studies compared bereavement-related depression with nonbereavement depression on a wide range of factors thought to be indicative of underlying psychopathology such as family history and future recurrence risk. The important difference between our studies concerns the issue of "complicated" bereavement, by which we mean a depressive episode occurring in the context of bereavement that is nevertheless severe (ie, associated with marked functional impairment, morbid preoccupation with worthlessness, suicidal ideation, psychomotor retardation, or psychotic symptoms) or prolonged (ie, duration $>2$ months). Complicated bereavement refers to bereavement-related depression that nonetheless qualifies for a diagnosis of MDE because of its severity or duration. Both of our studies are limited by the inability of the National Epidemiologic Survey on Alcohol and Related Conditions to fully operationalize the DSM criteria for complicated bereavement (eg, no assessment of psychotic symptoms).

The DSM-IV divides depressive episodes into 3 types: (1) bereavement-related depression that does not qualify for a diagnosis (what we termed bereavement-excluded depression); (2) complicated bereavement; and (3) depression unrelated to bereavement. The following predictions can be derived from the DSM-IV taxonomy: first, bereavement-excluded depression will score lower on external indicators of psychopathology than complicated bereavement and MDE, and second, complicated bereavement will score similarly on disorder indicators as MDE. In other words, the DSM-IV criteria would predict that group 1 would be less "disordered" than groups 2 and 3 and that groups 2 and 3 would be equally disordered. These predictions follow from the theoretical propositions that bereavement following the death of a loved one is common and should generally not be considered a psychiatric disorder and that some bereavement reactions do become severe enough to evolve into a psychiatric disorder.
Both of our studies supported the first predictionbereavement-related depression was in many ways less pathological than depression unrelated to bereavement. However, in the Mojtabai study, the second prediction was not thoroughly investigated. His primary analyses did not account for the presence of the DSM-IV's complicated features of bereavement-related depression (other than duration), and his secondary analyses (except for one comparison involving recurrence risk) grouped cases of complicated bereavement together with cases of depression unrelated to bereavement. As a result, the Mojtabai study addressed only one aspect of the bereavement exclusion.

In contrast, our analyses distinguished between bereavement-excluded depression and complicated bereavement in all comparisons. We found that complicated bereavement was much more similar to bereavementexcluded depression than it was to MDE-contrary to $D S M-I V ' s$ prediction. For example, cases of bereavementexcluded depression and complicated bereavement were both less likely to have a recurrence during 3 years of follow-up than individuals with MDE.

Mojtabai concluded that his results oppose the current draft recommendation for DSM-5 that eliminates the bereavement exclusion. We question this conclusion because we found no evidence to support the DSM-IV criteria for complicated bereavement. In our study, the DSM-IV criteria for complicated bereavement failed to identify cases of bereavement-related depression (ie, cases as severe as depression unrelated to bereavement).

In our opinion, decisions about the future of the bereavement exclusion should be guided by evidence concerning the validity of the exclusion as well as by evidence concerning the validity of the exception. This reflects what we view as a consensus on both sides of the debate against categorically excluding all bereavement-related depressions without any exception for "complicatedness."

Imposing a diagnostic threshold on an essentially dimensional construct ${ }^{4}$ entails trade-offs between overdiagnosis and underdiagnosis (or more precisely, sensitivity vs specificity). Questions raised about diagnosing depression occurring in the context of bereavement are motivated by a concern for overdiagnosis; we think it is equally important to address the exception to the bereavement exclusion to guard against underdiagnosis.

$$
\begin{aligned}
& \text { Stephen E. Gilman, } S c D \\
& \text { Joshua Breslau, PhD, ScD } \\
& \text { Nhi-Ha Trinh, MD, MPH } \\
& \text { Maurizio Fava, MD } \\
& \text { Jane M. Murphy, PhD } \\
& \text { Jordan W. Smoller, MD, ScD }
\end{aligned}
$$

Author Affiliations: Departments of Society, Human Development, and Health (Dr Gilman) and Epidemiology 
(Drs Gilman, Murphy, and Smoller), Harvard School of Public Health, and Department of Psychiatry, Massachusetts General Hospital (Drs Gilman, Trinh, Fava, Murphy, and Smoller), Boston; and RAND Corporation, Santa Monica, California (Dr Breslau).

Correspondence: Dr Gilman, Department of Society, Human Development, and Health, Harvard School of Public Health, 677 Huntington Ave, Boston, MA 02115 (sgilman @hsph.harvard.edu).

Conflict of Interest Disclosures: Dr Fava reports the following: research support from Abbott Laboratories; Alkermes Inc; Aspect Medical Systems; AstraZeneca; BioResearch; BrainCells Inc; Bristol-Myers Squibb; CeNeRx BioPharma; Cephalon; Clinical Trials Solutions LLC; Clintara LLC; Covance; Covidien; Eli Lilly and Company; EnVivo Pharmaceuticals Inc; Euthymics Bioscience Inc; Forest Pharmaceuticals Inc; Ganeden Biotech Inc; GlaxoSmithKline; Icon Clinical Research; i3 Innovus/Ingenix; Johnson \& Johnson Pharmaceutical Research \& Development; Lichtwer Pharma GmbH; Lorex Pharmaceuticals; National Alliance for Research on Schizophrenia and Depression; National Center for Complementary and Alternative Medicine; National Institute on Drug Abuse; National Institute of Mental Health; Novartis AG; Organon Pharmaceuticals; PamLab LLC; Pfizer Inc; Pharmavite LLC; Photothera; Roche Pharmaceuticals; RCT Logic LLC; sanofi-aventis US LLC; Shire; Solvay Pharmaceuticals Inc; Synthelabo; and Wyeth-Ayerst Laboratories; advisory/consulting fees from Abbott Laboratories; Affectis Pharmaceuticals AG; Alkermes Inc; Amarin Pharma Inc; Aspect Medical Systems; AstraZeneca; Auspex Pharmaceuticals; Bayer AG; Best Practice Project Management Inc; BioMarin Pharmaceuticals Inc; Biovail Corporation; BrainCells Inc; Bristol-Myers Squibb; CeNeRx BioPharma; Cephalon Inc; Clinical Trials Solutions LLC; CNS Response Inc; Compellis Pharmaceuticals; Cypress Pharmaceutical Inc; DiagnoSearch Life Sciences (P) Ltd; Dinippon Sumitomo Pharma Co Inc; Dov Pharmaceuticals Inc; Edgemont Pharmaceuticals Inc; Eisai Inc; Eli Lilly and Company; ePharmaSolutions; EPIX Pharmaceuticals Inc; Euthymics Bioscience Inc; FabreKramer Pharmaceuticals Inc; Forest Pharmaceuticals Inc; GenOmind LLC; GlaxoSmithKline; Grunenthal GmbH; i3 Innovus/Ingenix; Janssen Pharmaceutica; Jazz Pharmaceuticals Inc; Johnson \& Johnson Pharmaceutical Research \& Development; Knoll Pharmaceuticals Corp; Labopharm Inc; Lorex Pharmaceuticals; Lundbeck Inc; MedAvante Inc; Merck \& Co Inc; MSI Methylation Sciences Inc; Naurex, Inc; Neuronetics Inc; NextWave Pharmaceuticals; Novartis AG; Nutrition 21; Orexigen Therapeutics Inc; Organon Pharmaceuticals; Otsuka Pharmaceuticals; PamLab LLC; Pfizer Inc; PharmaStar; Pharmavite LLC; PharmoRx Therapeutics; Precision Human Biolaboratory; Prexa Pharmaceuticals Inc; Puretech Ventures; PsychoGenics; Psylin Neurosciences Inc; Rexahn Pharmaceuticals Inc; Ridge Diagnostics Inc; Roche; RCT Logic LLC; sanofi-aventis US LLC; Sepracor Inc; Servier Laboratories; Schering-Plough Corporation; Solvay Pharmaceuticals Inc; Somaxon Pharmaceuticals Inc; Somerset Pharmaceuticals Inc; Sunovion Pharmaceuticals; Supernus Pharmaceuticals Inc; Synthelabo; Takeda Pharmaceutical Company Limited; Tal Medical Inc; Tetragenex
Pharmaceuticals Inc; TransForm Pharmaceuticals Inc; Transcept Pharmaceuticals Inc; and Vanda Pharmaceuticals Inc; speaking fees/publishing royalties from Adamed Co; Advanced Meeting Partners; American Psychiatric Association; American Society of Clinical Psychopharmacology; AstraZeneca; Belvoir Media Group; Boehringer Ingelheim GmbH; Bristol-Myers Squibb; Cephalon Inc; CME Institute/Physicians Postgraduate Press Inc; Eli Lilly and Company; Forest Pharmaceuticals Inc; GlaxoSmithKline; Imedex LLC; Massachusetts General Hospital Psychiatry Academy/Primedia; Massachusetts General Hospital Psychiatry Academy/Reed Elsevier; Novartis AG; Organon Pharmaceuticals; Pfizer Inc; PharmaStar; United BioSource Corp; and Wyeth-Ayerst Laboratories; equity holdings in Compellis; a patent for Sequential Parallel Comparison Design and patent application for a combination of azapirone and bupropion in major depressive disorder; copyright royalties for the Massachusetts General Hospital Cognitive \& Physical Functioning Questionnaire, Sexual Functioning Inventory, Antidepressant Treatment Response Questionnaire, Discontinuation-Emergent Signs \& Symptoms, and SAFER; and a patent for research and licensing of Sequential Parallel Comparison Design with RCT Logic (Lippincott Williams \& Wilkins; Wolters Kluwer; and World Scientific Publishing Co Pte Ltd).

1. Mojtabai R. Bereavement-related depressive episodes: characteristics, 3-year course and implications for the DSM-5. Arch Gen Psychiatry. 2011;68(9):920-928.

2. Gilman SE, Breslau J, Trinh NH, Fava M, Murphy JM, Smoller JW. Bereavement and the diagnosis of major depressive episode in the National Epidemiologic Survey on Alcohol and Related Conditions. J Clin Psychiatry. 2012; 73(2):208-215

3. Wakefield JC, Schmitz MF, Baer JC. Did narrowing the major depression bereavement exclusion from DSM-III-R to DSM-IV increase validity?: evidence from the National Comorbidity Survey. J Nerv Ment Dis. 2011;199(2):66-73.

4. Kendler KS, Gardner CO Jr. Boundaries of major depression: an evaluation of DSM-IV criteria. Am J Psychiatry. 1998;155(2):172-177.

\section{In reply}

As Gilman and colleagues note in their letter, they came to a different conclusion from their analyses ${ }^{1}$ of bereavementrelated depressive episodes in the National Epidemiologic Survey of Alcohol and Related Conditions (NESARC) than I did. ${ }^{2}$ The important difference between our analyses is with regard to "complicated" bereavement, which they defined as

a depressive episode occurring in the context of bereavement that is nevertheless severe (ie, associated with marked functional impairment, morbid preoccupation with worthlessness, suicidal ideation, psychomotor retardation, or psychotic symptoms) or prolonged (ie, duration $>2$ months).

Gilman and colleagues found that complicated bereavement is not distinguishable from the bereavement-related episodes that would be excluded from the major depression category in DSM-IV (bereavement-excluded cases). On this basis, they questioned my conclusion that the NESARC results do not support the DSM-5 draft proposal to eliminate the bereavement exclusion.

Gilman and colleagues correctly note that my analyses of NESARC did not compare complicated bereavement with bereavement-unrelated major depressive episodes. ${ }^{2}$ This is because the variable of bereavement history in the released NESARC data on which my analyses were based was limited to depressive episodes that lasted less than 2 months. 
The numbers reported in the Gilman et al article 1 suggest that they used this same variable to identify their complicated bereavement cases. Using this variable, cases of complicated bereavement that lasted 2 or more months cannot be identified. Many bereavement-related depressive episodes in community samples last much longer than 2 months. ${ }^{3}$ Furthermore, a longer duration of these episodes is associated with greater severity and poorer course. ${ }^{3}$ Therefore, the conclusion of Gilman and colleagues that DSM-IV criteria cannot differentiate between bereavement-excluded cases and complicated bereavement ${ }^{1}$ may simply be a result of selective sampling of complicated bereavement cases with brief duration, which tend to be less severe and have a better course.

The argument by Gilman and colleagues for eliminating the bereavement exclusion also contains a logical flaw. Their finding of similarities between complicated bereavement and bereavement-excluded episodes and the striking differences between these cases and bereavement-unrelated major depressive episodes would argue for expanding the bereavement exclusion in DSM-5 to incorporate complicated bereavement cases, not eliminating the bereavement exclusion altogether. Expanding the bereavement exclusion criterion can be done by extending the duration allowed and/or by removing all or some of the severity indicators. Indeed, a number of recent studies have found that extending the duration would improve the validity of the bereavement exclusion criterion. . $^{3-5}$

Finally, Gilman and colleagues argue in their article that the bereavement exclusion is contradictory with the DSM as a "phenomenologically based nosology that purports not to incorporate assumptions about causal mechanisms into the diagnostic criteria."1(p214) However, many Axis I disorders in the DSM-IV exclude cases that meet the symptom criteria for these mental disorders but are caused by substances or general medical conditions. These exclusion criteria were maintained in the DSM-5 draft. Similar to these exclusion criteria, the bereavement exclusion criterion aims to improve the validity of the major depression category and provide diagnostic guidance for clinicians.

Ramin Mojtabai, MD, PhD, MPH

Author Affiliations: Department of Mental Health, Bloomberg School of Public Health, and Department of Psychiatry and Behavioral Sciences, Johns Hopkins University, Baltimore, Maryland.

Correspondence: Dr Mojtabai, Department of Mental Health, Johns Hopkins Bloomberg School of Public Health, 624 N Broadway, Room 797, Baltimore, MD 21205 (rmojtaba @jhsph.edu).

Conflict of Interest Disclosures: Dr Mojtabai has received research funding and consulting fees from BristolMyers Squibb and Lundbeck Pharmaceuticals.

1. Gilman SE, Breslau J, Trinh NH, Fava M, Murphy JM, Smoller JW. Bereavement and the diagnosis of major depressive episode in the National Epidemiologic Survey on Alcohol and Related Conditions. J Clin Psychiatry. 2012; 73(2):208-215

2. Mojtabai R. Bereavement-related depressive episodes: characteristics, 3-year course, and implications for the DSM-5. Arch Gen Psychiatry. 2011;68(9): 920-928.

3. Wakefield JC, Schmitz MF, Baer JC. Relation between duration and severity in bereavement-related depression. Acta Psychiatr Scand. 2011;124(6):487-494.

4. Wakefield JC, Schmitz MF, Baer JC. Did narrowing the major depression bereavement exclusion from DSM-III-R to DSM-IV increase validity?: evidence from the National Comorbidity Survey. J Nerv Ment Dis. 2011;199(2):66-73.
5. Wakefield JC, Schmitz MF. Recurrence of depression after bereavementrelated depression: evidence for the validity of DSM-IV bereavement exclusion from the Epidemiologic Catchment Area Study. J Nerv Ment Dis. 2012; 200(6):480-485

\section{Conflicts of Interest}

$\mathrm{O}$ hayon et al, the authors of "Operational Definitions and Algorithms for Excessive Sleepiness in the General Population: Implications for DSM-5 Nosology," did not make any financial disclosures. However, a brief Internet search demonstrates that 2 of the authors may have omitted relevant previously published pharmaceutical relationships. Ohayon and Dauvilliers had previously documented relationships with Cephalon Inc, ${ }^{2-5}$ who also funded their current study.

Given the Archives of General Psychiatry's policy of disclosing "all potential conflicts of interest, including specific financial interests. . . ." I am concerned about this apparent lack of transparency between published research supported by industry and authors' present and prior conflicts of interest.

\section{Stefan P. Kruszewski, MD}

Author Affiliations: Stefan P. Kruszewski MD \& Associates, Harrisburg, Pennsylvania.

Correspondence: Dr Kruszewski, Stefan P. Kruszewski MD \& Associates, 133 Linglestown Rd, Harrisburg, PA 17110 (skruszewski@spkmd.com).

Conflict of Interest Disclosures: Dr Kruszewski does not have any current business or financial arrangements with any pharmaceutical company. Prior to 2001, Dr Kruszewski participated on the speaker's bureaus of Pfizer Inc; GlaxoSmithKline; Watson; sanofi; Wyeth; Sandoz; Janssen (Johnson \& Johnson); AstraZeneca; Wallace Labs; Eli Lilly; and GE-Amersham Biosciences, and he previously served on an Eli Lilly Northeast Advisory Panel (1998). Dr Kruszewski has been hired as a general and case-specific expert in complex litigation involving OxyContin, Zyprexa, Neurontin, Zoloft, and bupropion. Dr Kruszewski has had 3 federal and state false claims settled as co-plaintiff with the United States: Southwood psychiatric facility; Pfizer (Geodon); and AstraZeneca (Seroquel).

1. Ohayon MM, Dauvilliers Y, Reynolds CF III. Operational definitions and algorithms for excessive sleepiness in the general population: implications for DSM-5 nosology. Arch Gen Psychiatry. 2012;69(1):71-79.

2. Ohayon MM, Vecchierini M-F. Normative sleep data, cognitive function and daily living activities in older adults in the community. Sleep. 2005;28(8): 981-989.

3. Ohayon MM. Determining the level of sleepiness in the American population and its correlates. J Psychiatr Res. 2012;46(4):422-427.

4. Billiard M, Bassetti C, Dauvilliers Y, Dolenc-Groselj L, Lammers GJ, Mayer G, Pollmächer T, Reading P, Sonka K; EFNS Task Force. EFNS guidelines on management of narcolepsy. Eur J Neurol. 2006;13(10):1035-1048.

5. Bayard S, Yu H, Langenier MC, Carlander B, Dauvilliers Y. Decision making in restless legs syndrome. Mov Disord. 2010;25(15):2634-2640.

6. Archives of General Psychiatry instructions for authors. Archives of General Psychiatry website. http://archpsyc .jamanetwork .com/public/InstructionsForAuthors .aspx\#ConflictsofInterestandFinancialDisclosure. Accessed March 1,2012 .

\section{In reply}

None of the authors received consultancies or honoraria; was on a speakers bureau; has stock ownership or options; provided expert testimony; or received royalties or any other 